\title{
Primary respiratory disease in patients with systemic lupus erythematosus: data from the Spanish rheumatology society lupus registry (RELESSER) cohort
}

Javier Narváez ${ }^{1 *}$ (D), Helena Borrell ${ }^{1}$, Fernando Sánchez-Alonso², Iñigo Rúa-Figueroa ${ }^{3}$, Francisco Javier López-Longo ${ }^{4}$, María Galindo-lzquierdo ${ }^{5}$, Jaime Calvo-Alén ${ }^{6}$, Antonio Fernández-Nebro ${ }^{7}$, Alejandro Olivé ${ }^{8}$, José Luis Andreu ${ }^{9}$, Víctor Martínez-Taboada ${ }^{10}$, Joan Miquel Nolla ${ }^{1}$, José María Pego-Reigosa ${ }^{11}$ and on behalf of the RELESSER Study Group

\begin{abstract}
Background: The purpose of this study was to assess the prevalence, associated factors, and impact on mortality of primary respiratory disease in a large systemic lupus erythematosus (SLE) retrospective cohort.

Methods: All adult patients in the RELESSER-TRANS (Registry of Systemic Lupus Erythematosus Patients of the Spanish Society of Rheumatology [SER], cross-sectional phase) registry were retrospectively investigated for the presence of primary pleuropulmonary manifestations.
\end{abstract}

Results: In total 3215 patients were included. At least one pleuropulmonary manifestation was present in 31\% of patients. The most common manifestation was pleural disease (21\%), followed by lupus pneumonitis (3.6\%), pulmonary thromboembolism (2.9\%), primary pulmonary hypertension (2.4\%), diffuse interstitial lung disease (2\%), alveolar hemorrhage (0.8\%), and shrinking lung syndrome $(0.8 \%)$.

In the multivariable analysis, the variables associated with the development of pleuropulmonary manifestation were older age at disease onset (odds ratio (OR) 1.03, 95\% confidence interval (Cl) 1.02-1.04), higher SLEDAl (Systemic Lupus Erythematosus Disease Activity Index) scores (OR 1.03, 95\% Cl 1.00-1.07), the presence of Raynaud's phenomenon (OR 1.41,95\% Cl 1.09-1.84), secondary antiphospholipid syndrome (OR 2.20, 95\% Cl 1.63-2.97), and the previous or concomitant occurrence of severe lupus nephritis, (OR 1.48, 95\% Cl 1.12-1.95) neuropsychiatric manifestations (OR 1.49, 95\% Cl 1.11-2.02), non-ischemic cardiac disease (OR 2.91, 95\% Cl 1.90-4.15), vasculitis (OR 1.81,95\% Cl 1.25-2.62), hematological manifestations (OR 1.31, 95\% Cl 1.00-1.71), and gastrointestinal manifestations, excluding hepatitis (OR 2.05, 95\% Cl 1.14-3.66). Anti-RNP positivity had a clear tendency to significance (OR 1.32, 95\% Cl 1.00-1.75; $P=0.054)$.

The development of pleuropulmonary manifestations independently contributes to a diminished survival (hazard ratio of 3.13). However, not all complications will influence the prognosis in the same way. Whereas the occurrence of pleural disease or pulmonary thromboembolism has a minimal impact on the survival of these patients, the remaining manifestations have a major impact on mortality.

(Continued on next page)

\footnotetext{
* Correspondence: fjnarvaez@bellvitgehospital.cat

'Department of Rheumatology (Planta 10-2), Servicio de Reumatología,

Hospital Universitario de Bellvitge, Feixa Llarga, s/n, Hospitalet de Llobregat,

08907 Barcelona, Spain

Full list of author information is available at the end of the article
}

(c) The Author(s). 2018 Open Access This article is distributed under the terms of the Creative Commons Attribution 4.0 International License (http://creativecommons.org/licenses/by/4.0/), which permits unrestricted use, distribution, and reproduction in any medium, provided you give appropriate credit to the original author(s) and the source, provide a link to the Creative Commons license, and indicate if changes were made. The Creative Commons Public Domain Dedication waiver (http://creativecommons.org/publicdomain/zero/1.0/) applies to the data made available in this article, unless otherwise stated. 
(Continued from previous page)

Conclusion: Except for pleural disease, the remaining respiratory manifestations are very uncommon in SLE (<4\%).

Pleuropulmonary manifestations independently contributed to a decreased survival in these patients.

Keywords: Systemic lupus erythematosus, Pleuropulmonary involvement

\section{Background}

Primary respiratory disease in systemic lupus erythematosus (SLE) seems not uncommon, although its exact prevalence is still unknown, since it has been reported to occur in $5 \%$ to $90 \%$ of the patients [1-6]. This wide range in prevalence may be explained by the characteristics of the patients studied (early or established disease), whether only symptomatic patients were included or systematic screening was done, the methodology used for diagnosis (clinical manifestations and imaging or autopsy findings), and the different study designs.

All components of the respiratory system may be affected during the course of disease. The spectrum of pulmonary manifestations caused by SLE includes pleural disease, upper and lower airway dysfunction, primary pulmonary hypertension, pulmonary thromboembolism, acute reversible hypoxemia, diffuse interstitial lung disease, acute lupus pneumonitis, diffuse alveolar hemorrhage, and shrinking lung syndrome [1-16]. Some patients may have more than one form of pleuropulmonary involvement during the course of their disease. The severity of these respiratory complications is highly variable and ranges from subclinical to potentially life-threatening conditions.

In general terms, primary respiratory involvement in SLE is not as well known as other major organ involvement. As in many other aspects of SLE, there is still no clear explanation for the appearance of such different respiratory manifestations in patients with an identical underlying disease. Although some associations have been described [1-6], the risk factors related to the occurrence of these complications are still unknown. It is likely that there are risk factors associated with the development of these complications, some of which may be modifiable.

The appearance of respiratory complications influences the prognosis (functional and vital) and the accumulated damage of the disease, although the extent and grade are still unknown. As the spectrum of pulmonary manifestations caused by SLE itself is very broad, not all complications will influence the prognosis in the same way.

The aim of the present study was to investigate the prevalence, risk factors, and impact on mortality of primary respiratory disease in patients from the multicenter Spanish SLE cohort RELESSER-TRANS (Registry of Systemic Lupus Erythematosus Patients of the Spanish Society of Rheumatology [SER], cross-sectional phase).

\section{Methods}

\section{Patient selection}

This is a historical study in which all adult patients in the RELESSER-TRANS registry were retrospectively investigated for the presence of primary pleuropulmonary manifestations.

The RELESSER-TRANS is a hospital-based registry involving a cross-sectional stage, designed to obtain a better understanding of SLE in clinical settings. It includes data from 3679 SLE patients (American College of Rheumatology [ACR]-1997 criteria) [17] from 45 Spanish hospitals. The methodologic and general characteristics of the RELESSER registry were published previously [18] (Additional file 1).

Pleuropulmonary manifestations analyzed in this study included (1) pleural disease, including patients with episodes of pleurisy according with the SELENA-SLEDAI (Systemic Lupus Erythematosus Disease Activity Index) definition [19], or pleural fibrosis according with the Systemic Lupus International Collaborating Clinics (SLICC)/ACR-damage index (SDI) [20] or both; (2) acute lupus pneumonitis or interstitial alveolitis/pneumonitis (in accordance with the British Isles Lupus Assessment group [BILAG] 2004 definition) [21, 22]; (3) diffuse interstitial lung disease or pulmonary fibrosis (SDI definition); (4) pulmonary hemorrhage (BILAG 2004 definition); (5) shrinking lung syndrome (BILAG 2004 definition); (6) primary pulmonary hypertension (SDI definition); and (7) pulmonary thromboembolism, including the cases registered with pulmonary infarction in accordance with the SDI definition. Upper and lower airway dysfunction and acute reversible hypoxemia were not included in the study as these two manifestations were not specifically recorded in the RELESSER database. Respiratory involvement was considered primary when it was directly related to SLE activity, and infections, drug toxicity, chronic obstructive pulmonary disease, occupational exposure, and neoplasia had been excluded.

The study protocol was approved by the institutional ethics committee of the Hospital Universitario Doctor Negrín and subsequently by the local ethics committee of all participating centers. Informed consent was obtained from the patients, and their clinical records and information were anonymized prior to analysis. Confidential information of the patients was protected in accordance with national norms. This study was conducted in accordance 
with the principles of the Declaration of Helsinki and the International Conference for Harmonization.

\section{Statistical analysis}

Numerical variables were expressed as mean or median and standard deviation. The categorical variables were described by absolute frequency and percentage.

Comparisons of numerical variables were obtained by using a Student $t$ test or a Mann-Whitney $U$ test, according to normality adjustments, and of categorical variables by using a chi-squared or Fisher's exact test as necessary.

Variables reaching statistical significance in the unadjusted analysis were entered in a multivariate model (Cox proportional hazards regression) to identify risk factors for the development of pleuropulmonary complications. The selection of variables in the model was made while taking into account its individual association, the multicollinearity between different variables, and its importance as a confounding factor that justified its inclusion as an adjustment variable.

Survival analysis (Kaplan-Meier) was conducted to assess whether the development of respiratory disease was associated with lower survival in patients with lupus and to explore the influence on the prognosis of each analyzed respiratory manifestation. Subsequent comparisons between survival curves were made by using a log-rank test.

To determine the independent contribution of the presence of pleuropulmonary manifestations to mortality, a multivariable Cox regression analysis was carried out. The following variables were considered candidates for inclusion: age, gender, infections, nephritis, cardiac involvement, cardiovascular and cerebrovascular events, and SLEDAI and SLICC scores. Pleuropulmonary manifestations were considered a time-dependent variable. Statistical significance was assumed as a $P$ value of less than 0.05 .

\section{Results}

\section{Demographic data}

Of the 3679 patients included in the RELESSER-TRANS, 3215 patients were finally included in this study (after excluding those in whom respiratory manifestations had not been collected and cases in which there were doubts as to whether the pulmonary condition could be directly related to SLE activity). Of these, 91\% were female and 9\% were male; mean age at SLE diagnosis ( \pm standard deviation) was $37 \pm 13$ years (range 19-86), and median disease duration was $118 \pm 98$ months (range 61-196). The main baseline demographic and clinical characteristics of the SLE study cohort are shown in Table 1.

\section{Pleuropulmonary manifestations}

At least one pleuropulmonary manifestation was present in 996 patients (31\%): 920 patients developed one manifestation, 56 two, 19 three, and 1 four. The most common manifestation was pleural disease, occurring in 680 (21\%) of patients, followed by lupus pneumonitis in 118 (3.6\%), pulmonary thromboembolism in 95 (2.9\%), primary pulmonary hypertension in $79(2.4 \%)$, diffuse interstitial lung disease in 65 (2\%), alveolar hemorrhage in 28 $(0.8 \%)$, and shrinking lung syndrome in $28(0.8 \%)$.

Respiratory manifestations may complicate SLE at any time during its course, although they usually occur later in the course of the disease. The mean time from diagnosis of SLE to the first appearance of respiratory manifestations was 5.8 (standard deviation 8.3) years; the mean disease duration for each manifestation was pleurisy 7.6 years (8.6), acute lupus pneumonitis 5.4 years (7.6), diffuse interstitial lung disease/pulmonary fibrosis 7.7 years (10.5), alveolar hemorrhage 5.2 years (7.5), shrinking lung syndrome 6 years (6.8), primary pulmonary hypertension 9.2 years (9.2), and pulmonary thromboembolism 3.9 years (7.9). In $4 \%$ of the cases, respiratory manifestations were the presenting symptoms of SLE (including cases of pleurisy, shrinking lung syndrome, and diffuse alveolar hemorrhage). Twenty-two percent of patients with acute lupus pneumonitis (26 out of 118) and $21 \%$ of patients with alveolar hemorrhage ( 6 out of 28 ) who survived finally developed pulmonary fibrosis.

\section{Other previous and concomitant clinical manifestations of SLE}

As shown in Table 1, the majority of patients who developed pleuropulmonary manifestations also had previous or concomitant involvement of other major organs. The most common clinical features of lupus were arthritis and dermatologic involvement and, less commonly, pericarditis. Nephritis was documented in 39\% of the patients, non-ischemic cardiac disease in $16 \%$, neuropsychiatric involvement in $11 \%$, vasculitis in $8 \%$, and gastrointestinal involvement in $5 \%$.

In regard to their autoantibody profiles, $72 \%$ of patients tested positive for anti-double stranded DNA antibodies and $76.5 \%$ had hypocomplementemia at some time during the course of the disease. Anti-Sm antibodies were positive in $21 \%$, anti-RNP in $25 \%$, and anti-Ro in $40 \%$ of the patients in whom this information was available. The frequency of antiphospholipid antibody (aPL) positivity was also remarkable: anticardiolipin antibodies (IgM or IgG) 20\%, anti-beta-2 glycoprotein 1 (IgM or IgG) $13.5 \%$, and lupus anticoagulant $23 \%$.

Patients with respiratory complications had higher S-SLEDAI scores $(3.65 \pm 2.25$ versus $2.72 \pm 2.43 ; P$ $<0.001$ ) at the last visit (when enrollment in the registry occurred). As expected, the mean SDI scores were also 
Table 1 Baseline demographic and clinical characteristics of the systemic lupus erythematosus study cohort

\begin{tabular}{|c|c|}
\hline \multicolumn{2}{|l|}{ Demographic characteristics } \\
\hline Number of patients & 3215 \\
\hline Women/Men & $2925(91 \%) / 290(9 \%)$ \\
\hline $\begin{array}{l}\text { Age at SLE diagnosis, mean } \\
\pm \mathrm{SD}\end{array}$ & $37 \pm 13$ (range, 19-86 years) \\
\hline $\begin{array}{l}\text { Age at the time of RELESSER- } \\
\text { TRANS inclusion, mean } \pm \text { SD }\end{array}$ & $48 \pm 14$ (range, 19-94 years) \\
\hline Ethnic groups & $\begin{array}{l}\text { Caucasians: } 93 \% / \text { Hispanics: } 5 \\
\text { African-Americans: } 0.2 \% / \text { Asia } \\
\text { 0.6\%/Others: } 0.8 \%\end{array}$ \\
\hline Tobacco & $\begin{array}{l}\text { Never: } 58 \% / \text { Before: } 25 \% / A t \text { th } \\
\text { of RELESSER-TRANS inclusion }\end{array}$ \\
\hline \multicolumn{2}{|l|}{ Clinical manifestations } \\
\hline Constitutional symptoms & Fever 3.6\%/Weight loss 9.5\% \\
\hline Cutaneous & $64 \%$ \\
\hline Arthritis & $78 \%$ \\
\hline Raynaud's phenomenon & $35 \%$ \\
\hline Vasculitis & $10 \%$ \\
\hline Nephritis & $31 \%$ \\
\hline Gastrointestinal involvement & $3 \%$ \\
\hline Hepatitis & $2.8 \%$ \\
\hline Pericarditis & $15 \%$ \\
\hline Non-ischemic cardiac disease & $4.5 \%$ \\
\hline Neuropsychiatric manifestations & $6.5 \%$ \\
\hline Hematologic & $79 \%$ \\
\hline $\begin{array}{l}\text { Lymphadenopathy/ } \\
\text { Splenomegaly }\end{array}$ & $9.7 \% / 2.9 \%$ \\
\hline $\begin{array}{l}\text { Secondary antiphospholipid } \\
\text { syndrome }\end{array}$ & $17 \%$ \\
\hline SLEDAI score, mean \pm SD & $2.62 \pm 3.69$ \\
\hline SDI score, mean \pm SD & $1.15 \pm 1.68$ \\
\hline \multicolumn{2}{|l|}{ Immunological laboratory ${ }^{*}$} \\
\hline $\begin{array}{l}\text { Anti-dsDNA antibody positivity } \\
\text { (available data in all patients) }\end{array}$ & $72 \%$ \\
\hline $\begin{array}{l}\text { Hypocomplementemia } \\
\text { (available data in all patients) }\end{array}$ & $76.5 \%$ \\
\hline $\begin{array}{l}\text { Anti-Sm antibody positivity } \\
\text { (available in } 3048 \text { patients) }\end{array}$ & $21 \%$ \\
\hline $\begin{array}{l}\text { Anti-Ro antibody positivity } \\
\text { (available in } 3109 \text { patients) }\end{array}$ & $40 \%$ \\
\hline $\begin{array}{l}\text { Anti-La antibody positivity } \\
\text { (available in } 3108 \text { patients) }\end{array}$ & $19 \%$ \\
\hline $\begin{array}{l}\text { Anti-RNP antibody positivity } \\
\text { (available in } 3095 \text { patients) }\end{array}$ & $25 \%$ \\
\hline $\begin{array}{l}\text { Anticardiolipin antibody } \\
\text { positivity [lgM or lgG] } \\
\text { (available in } 2952 \text { patients) }\end{array}$ & $20 \%$ \\
\hline $\begin{array}{l}\text { Anti-beta } 2 \text { glycoprotein } 1 \\
\text { [lgM or lgG] (available in } \\
1918 \text { patients) }\end{array}$ & $13.5 \%$ \\
\hline
\end{tabular}

Table 1 Baseline demographic and clinical characteristics of the systemic lupus erythematosus study cohort (Continued)

\begin{tabular}{ll}
\hline $\begin{array}{l}\text { Lupus anticoagulant } \\
\text { (available in } 2312 \text { patients) }\end{array}$ & $23 \%$ \\
$\begin{array}{l}\text { Treatments } \\
\text { (* }\end{array}$ & \\
Corticosteroids & $88 \%$ \\
$\quad<10 \mathrm{mg} /$ daily of prednisone & $46.5 \%$ \\
or equivalent & \\
$\quad 10-30 \mathrm{mg} /$ daily & $32 \%$ \\
$>30-60$ mg/daily & $21.5 \%$ \\
Antimalarials & $83.5 \%$ \\
Methotrexate & $17 \%$ \\
Azathioprine & $31 \%$ \\
Cyclophosphamide & $20 \%$ \\
Mycophenolate & $16 \%$ \\
Intravenous immunoglobulins & $4 \%$ \\
Plasmapheresis & $1.5 \%$ \\
Rituximab & $6 \%$ \\
Antiplatelet therapy & $36 \%$ \\
Anticoagulants & $14 \%$
\end{tabular}

Abbreviations: RELESSER-TRANS Registry of Systemic Lupus Erythematosus Patients of the Spanish Society of Rheumatology [SER], cross-sectional phase, $S D$ standard deviation, SDI Systemic Lupus International Collaborating Clinics/ American College of Rheumatology Damage Index, SLE systemic lupus erythematosus, SLEDAl Systemic Lupus Erythematosus Disease Activity Index "Because this is a retrospective (historical) study, not all analyzed variables were recorded in all included cases. Thus, the percentage for each variable was calculated for only those patients in which the data were documented ** Treatments recorded in the RELESSER-TRANS registry as "any use" or "use at last visit" (corresponding to the last visit before enrollment) or both

significantly higher in this group than in patients with no pleuropulmonary involvement $(2.39 \pm 3.34$ versus $0.90 \pm 1.40 ; P<0.001)$. Of interest, when lung manifestations were excluded from the SDI, the differences remained $(1.57 \pm 2.13$ versus $0.62 \pm 1.22 ; P<0.01)$. From these data it can be inferred that the development of respiratory complications has an important weighting in the accumulated damage of the disease.

\section{Factors associated with the development of pleuropulmonary complications}

The results of the univariate and multivariate analysis are shown in Table 2 . In the multivariate analysis, the variables independently associated with the development of pleuropulmonary manifestation were older age at disease onset (odds ratio (OR) 1.03, 95\% confidence interval (CI) 1.021.04), higher SLEDAI scores (OR 1.03, 95\% CI 1.00-1.07), the presence of Raynaud's phenomenon (OR 1.41, 95\% CI 1.09-1.84), secondary antiphospholipid syndrome (OR 2.20, 95\% CI 1.63-2.97), and the previous or concomitant occurrence of severe lupus nephritis (including classes III, IV, V, and mixed III/IV + V) (OR 1.48, 95\% CI 1.12-1.95), neuropsychiatric manifestations (OR 1.49, 95\% CI 1.11- 
Table 2 Variables associated with the development of pleuropulmonary manifestations

\begin{tabular}{|c|c|c|c|c|c|}
\hline & \multirow{2}{*}{$\begin{array}{l}\text { Without pleuropulmonary } \\
\text { involvement }(N=2219)\end{array}$} & \multirow{2}{*}{$\begin{array}{l}\text { With pleuropulmonary } \\
\text { involvement }(N=996)\end{array}$} & \multirow{2}{*}{$\begin{array}{l}\text { Univariate } \\
\text { analyses } \\
P \text { value }\end{array}$} & \multicolumn{2}{|l|}{ Multivariate analyses } \\
\hline & & & & Odds ratio $(95 \% \mathrm{Cl})$ & $P$ value \\
\hline Gender, female (\%) & $91.5 \%(2030)$ & $88.3 \%(880)$ & 0.053 & $0.86(0.57-1.29)$ & 0.450 \\
\hline Age at SLE onset, mean \pm SD & $37 \pm 11.6$ & $39.1 \pm 13$ & $<0.001$ & $1.03(1.02-1.04)$ & 0.001 \\
\hline $\begin{array}{l}\text { Tobacco (before or at the time of RELESSER-TRANS } \\
\text { inclusion) }\end{array}$ & $41.4 \%(919)$ & $45.2 \%(450)$ & 0.015 & $1.13(0.88-1.45)$ & 0.350 \\
\hline \multicolumn{6}{|l|}{ Clinical manifestations } \\
\hline Arthritis & $77.3 \%(1717)$ & $80 \%(797)$ & 0.257 & $1.35(0.99-1.85)$ & 0.069 \\
\hline Cutaneous & $64.9 \%(1440)$ & $62.6 \%(623)$ & 0.568 & & \\
\hline Raynaud's phenomenon & $32.6 \%(723)$ & $41.9 \%(417)$ & $<0.001$ & $1.41(1.09-1.84)$ & 0.015 \\
\hline Vasculitis & $7.2 \%(160)$ & $17.6 \%(175)$ & $<0.001$ & $1.81(1.25-2.62)$ & 0.002 \\
\hline Nephritis & $26.8 \%(595)$ & $39 \%(389)$ & 0.043 & $1.30(0.98-1.73)$ & 0.068 \\
\hline $\begin{array}{l}\text { Severe lupus nephritis (only including classes III, IV, } \\
V \text {, and mixed III/IV + V) }\end{array}$ & $20.2 \%(450)$ & $26.7 \%(266)$ & $<0.001$ & $1.48(1.12-1.95)$ & 0.002 \\
\hline Non-ischemic cardiac disease, excluding pericarditis & $2.3 \%(52)$ & $9.3 \%(93)$ & $<0.001$ & $2.91(1.90-4.15)$ & 0.001 \\
\hline Gastrointestinal involvement, except hepatitis & $2.2 \%(49)$ & $5.3 \%(53)$ & 0.001 & $2.05(1.14-3.66)$ & 0.016 \\
\hline Hepatitis & $2.3 \%(51)$ & $3.9 \%(39)$ & 0.078 & $0.75(0.35-1.60)$ & 0.453 \\
\hline Hematologic abnormalities & $76.7 \%(1701)$ & $84.3 \%(840)$ & 0.001 & $1.31(1.00-1.71)$ & 0.048 \\
\hline Neuropsychiatric manifestations & $4.4 \%(98)$ & $(112)$ & $<0.001$ & $1.49(1.11-2.02)$ & 0.009 \\
\hline Secondary antiphospholipid syndrome & $12 \%(266)$ & $27.9 \%(278)$ & $<0.001$ & $2.20(1.63-2.97)$ & 0.000 \\
\hline SLEDAI score, mean \pm SD & $2.72 \pm 2.43$ & $3.65 \pm 2.25$ & $<0.001$ & $1.03(1.00-1.07)$ & 0.021 \\
\hline SDI score, mean \pm SD & $0.90 \pm 1.40$ & $2.39 \pm 3.34$ & $<0.001$ & & \\
\hline \multicolumn{6}{|l|}{ Immunological laboratory* } \\
\hline Anti-dsDNA antibody positivity & $71.3 \%(1978 / 2772)$ & $76.7 \%(277 / 361)$ & 0.072 & & \\
\hline Hypocomplementemia & $76.2 \%(2123 / 2785)$ & $77.9 \%(278 / 357)$ & 0.085 & & \\
\hline Anti-Sm antibody positivity & $20.2 \%(545 / 2701)$ & $23.6 \%(82 / 347)$ & 0.134 & & \\
\hline Anti-Ro antibody positivity & $40.8 \%(1126 / 2760)$ & $36.1 \%(126 / 349)$ & 0.092 & & \\
\hline Anti-La antibody positivity & $19.7 \%(543 / 2756)$ & $16.5 \%(58 / 352)$ & 0.149 & & \\
\hline Anti-RNP antibody positivity & $23.9 \%(657 / 2744)$ & $30.5 \%(107 / 351)$ & 0.007 & $1.32(1.00-1.75)$ & 0.054 \\
\hline Anticardiolipin antibody positivity (IgM or lgG) & $19.9 \%(520 / 2616)$ & $21.7 \%(73 / 336)$ & 0.426 & & \\
\hline Anti-beta 2 glycoprotein 1 (IgM or lgG) & $13.3 \%(226 / 1697)$ & $14.9 \%(33 / 221)$ & 0.509 & & \\
\hline Lupus anticoagulant & $22.2 \%(455 / 2049)$ & $30.1 \%(82 / 272)$ & 0.004 & & \\
\hline
\end{tabular}

Results are presented as percentage (and number of cases) or mean \pm standard deviation

Abbreviations: Cl confidence interval, RELESSER-TRANS Registry of Systemic Lupus Erythematosus Patients of the Spanish Society of Rheumatology [SER], crosssectional phase, SD standard deviation, SDI Systemic Lupus International Collaborating Clinics/American College of Rheumatology Damage Index, SLE systemic lupus erythematosus, SLEDA/ Systemic Lupus Erythematosus Disease Activity Index

*Because this is a retrospective (historical) study, not all analyzed variables were available in all included cases. Thus, the percentage for each variable was calculated for only those patients in which the data were documented Statistical significance was assumed as a $p$ value of less than 0.05 (bold data)

2.02), non-ischemic cardiac disease (OR 2.91, 95\% CI 1.904.15), vasculitis (OR 1.81, 95\% CI 1.25-2.62), hematological manifestations (OR 1.31, 95\% CI 1.00-1.71), and gastrointestinal manifestations, excluding hepatitis (OR 2.05, 95\% CI 1.14-3.66). Anti-RNP positivity had a clear tendency to significance (OR 1.32, 95\% CI 1.00-1.75; $P=0.054$ ).

\section{Mortality}

Sixty-one patients with pleuropulmonary manifestations (1.89\%) died over the follow-up period. SLE was the commonest cause of death, occurring in $0.9 \%$ of patients (28 out of 3215), followed by infection in $0.5 \%$ (17 out of 3215), cardiovascular and cerebrovascular disease in $0.3 \%$ (11 out of 3215), and cancer in $0.1 \%$ (5 out of 3215). Although the mortality rate was low, the development of respiratory disease was associated with lower survival (survival rates $95.6 \%$ versus $82.2 \%, P=0.030$; Fig. 1). After adjustment for known confounders in the multivariable Cox regression model (Table 3), pleuropulmonary manifestations remained a risk factor for 


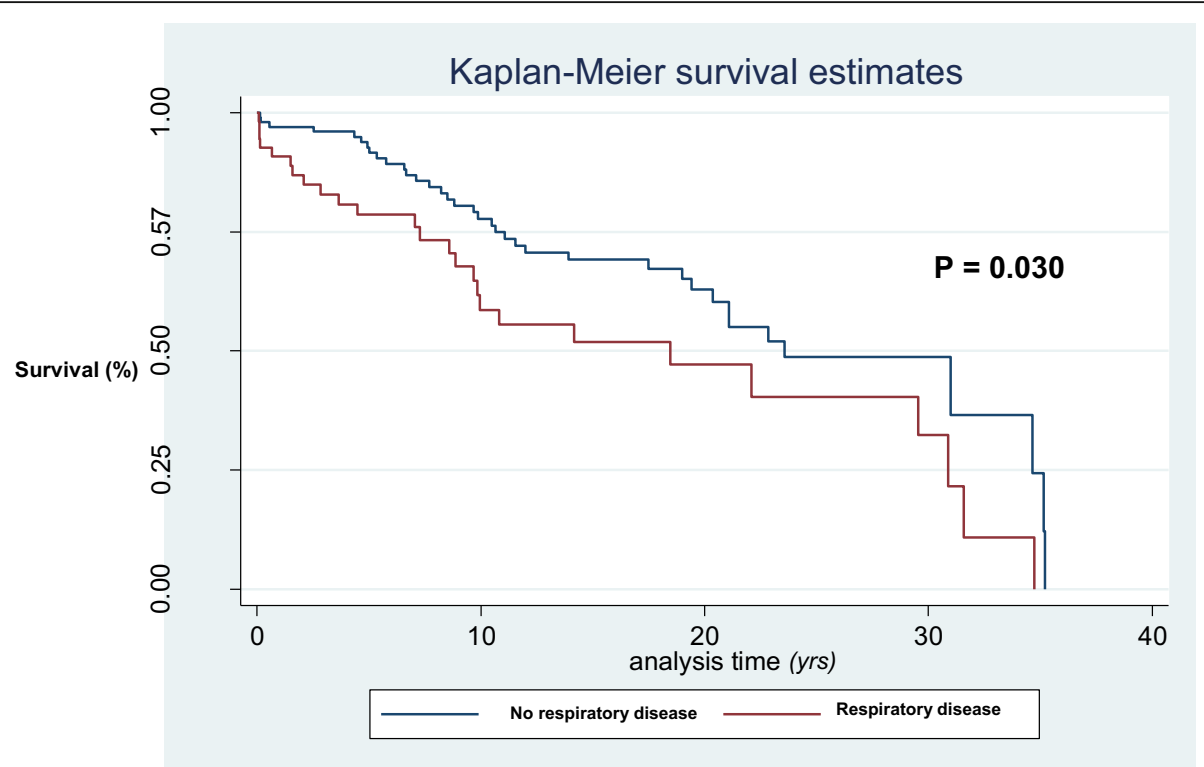

Fig. 1 Survival analysis (Kaplan-Meier) comparing patients with and without primary respiratory disease

diminished survival (hazard ratio 3.13, 95\% CI 1.566.28, $P=0.001$ ).

Since not all complications influenced the prognosis in the same way, survival analysis analyzing the presence of each individual respiratory manifestation was conducted: (1) considering only the presence of pleural disease: survival rates of $82.9 \%$ versus $95.6 \%$ (no pleuritis) $(P=$ $0.101)$; (2) considering only the presence of pulmonary thromboembolism: survival rates of $88.7 \%$ versus $95.6 \%$ ( $P=0.253)$; (3) considering only the presence of shrinking lung syndrome: survival rates of $80.9 \%$ versus $95.6 \%$ $(P=0.567)$; (4) considering only the presence of diffuse interstitial lung disease: survival rates of $79.7 \%$ versus 95.6\% ( $P<0.01)$; $(5)$ considering only the presence of pneumonitis: survival rates of $78.6 \%$ versus $95.6 \%(P$ $<0.01)$; (6) considering only the presence of primary pulmonary hypertension: survival rates of $76.1 \%$ versus
95.6\% $(P<0.01)$; and $(7)$ considering only the presence of alveolar hemorrhage: survival rates of $55.6 \%$ versus 95.6\% $(P<0.001)$.

\section{Discussion}

The heterogeneity of disease course and outcome in SLE, coupled with its low prevalence, make it difficult for physicians to acquire sufficient clinical experience in the absence of standardization and collaborative efforts. Therefore, much of the clinical research on SLE has been based primarily on registries and on their derived cohorts, which have been an important source of new knowledge about the disease. Studies derived from registries usually have a large number of patients from non-experimental clinical settings and allow a more extensive follow-up than can be accomplished in clinical trials, providing more reliable answers to specific

Table 3 Cox regression of predictors of mortality in lupus patients from the RELESSER-TRANS cohort

\begin{tabular}{llll}
\hline & Hazard ratio & $95 \%$ confidence interval & $P$ value \\
\hline Pleuropulmonary manifestations & 3.13 & $1.56-6.28$ & 0.001 \\
Age & 0.99 & $0.96-1.01$ & 0.293 \\
Gender & 0.89 & $0.31-2.52$ & 0.825 \\
Infections & 0.79 & $0.39-1.59$ & 0.506 \\
Nephritis & 0.74 & $0.23-2.39$ & 0.612 \\
Cardiac disease & 1.01 & $0.42-2.42$ & 0.978 \\
Cardiovascular events & 1.57 & $0.32-7.66$ & 0.577 \\
SLEDAl score & 1.08 & $1.00-1.16$ & 0.052 \\
SLICC score & 1.79 & $0.69-0.92$ & 0.002 \\
\hline
\end{tabular}

Abbreviations: RELESSER-TRANS Registry of Systemic Lupus Erythematosus Patients of the Spanish Society of Rheumatology [SER], cross-sectional phase, SLEDAI Systemic Lupus Erythematosus Disease Activity Index, SLICC Systemic Lupus International Collaborating Clinics 
questions. In this case, this applied to primary respiratory involvement in SLE, which is not as well known as other major organ involvement.

According to the data from our registry, the overall prevalence of symptomatic pleuropulmonary manifestations in this SLE population was 31\%, and pleural involvement was the most frequent complication. This prevalence is higher than that reported in the Eurolupus project (7\%) [23] and is similar to that reported in the Latin American SLE cohort (Grupo Latinoamericano de Estudio del Lupus, or GLADEL), which recently examined this specific clinical aspect (28\%) [2]. Prevalence rates from these three multicenter registries demonstrate that primary respiratory disease occurs in about $25-30 \%$ of patients with lupus during the course of the disease.

Apart from pleural disease that occurs in $21 \%$ of patients, the other respiratory manifestations are uncommon, occurring in less than $4 \%$ of cases. Of the lung parenchymal manifestations, the most commonly observed was pneumonitis (3.6\%). This is consistent with observations from other registries in which it was also the most frequent parenchymal complication; the reported prevalence was between $2.4 \%$ and $4 \%$ [2, 24].

Pleuropulmonary involvement may complicate SLE at any time during its course, although it is more frequent later in the course of the disease (mean disease duration of about 6 years). Data from the LUMINA (Lupus in minorities: nature versus nurture) multiethnic cohort also documented the development of pulmonary damage (as defined by SDI) after a mean disease duration of 5.3 years [13]. More rarely ( $4 \%$ of cases in our study), respiratory complications may be the presenting manifestation of SLE. This has been described with pleurisy, shrinking lung syndrome, diffuse alveolar hemorrhage, acute lupus pneumonitis, and pulmonary thromboembolism [14, 16, 24, 25].

In most patients, pleuropulmonary involvement occurs in the setting of previous or concomitant involvement of other major organs. Apart from the frequent presence of systemic, cutaneous, and musculoskeletal symptoms, a considerable proportion of these patients have or have had nephritis (39\% in our series and $40 \%$ of cases in the GLADEL registry), neuropsychiatric involvement (11\% and $14 \%$, respectively), and non-ischemic heart disease (16\% and $14 \%$, respectively) [2]. According to our study, the history of pericarditis, vasculitis, and gastrointestinal involvement is also frequent in this group of patients. From these data it can be inferred that the development of respiratory complications occurs in patients with a severe disease, with higher mean SDI scores even when lung manifestations are excluded.

In fact, patients with active disease (defined by higher SLEDAI scores) and the previous or concomitant presence of severe lupus nephritis, neuropsychiatric manifestations, non-ischemic cardiac disease, hematological manifestations, and gastrointestinal involvement, those with Raynaud's phenomenon, and those who had secondary antiphospholipid syndrome are predisposed to the occurrence of pleuropulmonary manifestations. Another predictive factor is older age. It cannot be ruled out that, in addition to antiphospholipid antibodies, anti-RNP antibodies could be related to the development of pleuropulmonary manifestations; in our study, anti-RNP positivity had a clear tendency to significance (OR 1.32, 95\% CI $1.00-1.75 ; P=0.054$ ) and previous investigations support this relationship.

Some of these associated factors are coincident with those reported in other studies. In the LUMINA registry, older age and the presence of anti-RNP antibodies were associated with a shorter time to the development of permanent lung disease [13]. In the GLADEL registry, older age and the presence of systemic symptoms, non-ischemic heart disease, and nephritis were also associated with the occurrence of pleuropulmonary manifestations [2].

A strong association between aPL and pulmonary thromboembolism has been well documented in SLE [26]. In addition, new evidence suggests that aPL in patients with SLE increases the risk of primary pulmonary hypertension [27]. Hypotheses regarding the impact of aPL on pulmonary hypertension include large vessel and microvascular thrombosis and endothelial remodeling [27]. Diffuse alveolar hemorrhage may rarely occur in antiphospholipid syndrome and may be the initial manifestation [28]. The proposed mechanism in SLE is a necrotizing microangiitis related to immune complex deposition and induction of apoptosis, involving alveolar capillaries [29]. In antiphospholipid syndrome, histopathological studies show alveolar hemorrhage and microvascular thrombosis with or without pulmonary capillaritis [30]. The fact that SLE and antiphospholipid syndrome have a wide spectrum of pulmonary manifestations, some of which may be very similar, has raised the question of common pathological processes [31]. Finally, a greater frequency of Raynaud's phenomenon in patients with SLE and primary pulmonary hypertension has been documented (60\% versus $20 \%-30 \%$ in those without this complication) [32]. Shen et al. have shown that patients with pulmonary hypertensive SLE had higher serum endothelin levels, their lupus was more active, and they presented with Raynaud's phenomenon, suggesting that pulmonary arterial vasospasm could play an important role in the pathogenesis of this complication [33]. Finally, Wang et al., in a recently published meta-analysis, identified the anti-RNP antibody and anti-Sm antibody as risk factors for SLE-associated pulmonary arterial hypertension with pooled ORs of 3.68 (95\% CI 2.04-6.63, $P<0.0001)$ and 1.71 (95\% CI 1.06$2.76, P=0.03)$, respectively [34]. Seropositivity for 
anti-RNP has also been described as a risk factor for the development of shrinking lung syndrome but this association has not been confirmed in all of the studies [16, 35, 36]. Previous investigations have documented a relationship between anti-Ro, anti-La, and anti-Sm antibodies with some pulmonary manifestations, but we could not corroborate these associations [2, 37-39].

Primary respiratory disease is an important cause of morbidity and mortality in SLE. In a previous study from our group, pleuropulmonary manifestations represented $3.7 \%$ of the total accumulated damage of the disease in the patients included in the RELESSERTRANS as defined by the SDI [40]. As stated in the LUMINA cohort, cumulative rates of pulmonary damage at 5 and 10 years are $7.6 \%$ and $11.6 \%$, respectively [13]. Another important finding is that $21 \%-22 \%$ of our patients with acute lupus pneumonitis or alveolar hemorrhage who survived finally developed pulmonary fibrosis.

Consistent with previous reports, our study corroborates the fact that pleuropulmonary manifestations independently contribute to a diminished survival $[2,41,42]$. However, not all complications will influence the prognosis in the same way. Whereas the occurrence of pleural disease or pulmonary thromboembolism has a minimal impact on the survival of these patients, the remaining manifestations have a major impact on mortality (in order of least to most important: shrinking lung syndrome, diffuse interstitial lung disease, pneumonitis, primary pulmonary hypertension, and alveolar hemorrhage).

This is a retrospective (historical) study carved into an existing cohort and has several limitations. First, the main limitation is that the baseline variables were collected many years into the course of the disease rather than at onset. Second, owing to the multipurpose nature of the RELESSER-TRANS registry, which was never specifically designed to study primary respiratory disease in SLE, pleuropulmonary manifestations were not systematically evaluated, and only the symptomatic cases were collected. This could lead to an underestimation of the frequency of some of these manifestations. Third, not all autoantibodies were available in all patients, and had not been obtained at a central laboratory or at the time pleuropulmonary manifestations occurred. Fourth, we could not exclude random associations due to the large number of variables analyzed. However, we have tried to minimize this risk by using multivariate analysis. Fifth, the main objectives of this registry did not include analysis of the specific effects of therapies on individual manifestations. For this reason, in the multivariable Cox regression model of mortality, we have not included medications known to be either protective (antimalarials) or deleterious (steroids).

\section{Conclusions}

Except for pleural disease, the remaining respiratory manifestations are very uncommon in patients with SLE, occurring in less than $4 \%$ of cases. Of the lung parenchymal manifestations, the most commonly observed was pneumonitis (3.6\%).

They occur later in the course of the disease, mainly in patients with active and severe lupus (with previous or concomitant major organ involvement other than lung), and seem to be associated with older age, the presence of Raynaud's phenomenon, and the positivity of antiphospholipid antibodies. Pleuropulmonary manifestations contribute independently to a significantly decreased survival. However, not all complications will influence the prognosis in the same way. Whereas the occurrence of pleural disease or pulmonary thromboembolism has a minimal impact on the survival of these patients, the remaining manifestations have a major impact on mortality.

\section{Additional file}

Additional file 1: Information about the RELESSER-TRANS registry. (DOCX $15 \mathrm{~kb}$ )

\section{Abbreviations \\ ACR: American College of Rheumatology; aPL: Antiphospholipid antibody; BILAG: British Isles Lupus Assessment group; Cl: Confidence interval; GLADEL: Grupo Latinoamericano de Estudio del Lupus; LUMINA: Lupus in minorities: nature versus nurture; OR: Odds ratio; RELESSER: Registry of Systemic Lupus Erythematosus Patients of the Spanish Society of Rheumatology; RELESSER-TRANS: Registry of Systemic Lupus Erythematosus Patients of the Spanish Society of Rheumatology [SER], cross-sectional phase; SDI: Systemic Lupus International Collaborating Clinics (SLICC)-Damage Index; SELENA-SLEDAI: Safety of Estrogens in Lupus Erythematosus National Assessment-Systemic Lupus Erythematosus Disease Activity Index; SLE: Systemic lupus erythematosus; SLEDAl: Systemic Lupus Erythematosus Disease Activity Index; SLICC: Systemic Lupus International Collaborating Clinics}

\section{Acknowledgments}

RELESSER Collaborators:

Paloma Vela, Hospital General Universitario de Alicante, Alicante (vela_pal@gva.es)

Elia Vals, Hospital Universitario Dr. Peset, Valencia (elialtea@gmail.com) Tatiana Cobo-lbáñez, Hospital Universitario Reina Sofía, Madrid

(mtcoboiba@yahoo.es)

Gema Bonilla, Hospital Universitario La Paz, Madrid (gemabonilla@ser.es) María Jesús García-Villanueva, Hospital Universitario Ramón y Cajal, Madrid (machusgv@gmail.com)

Elvira Diez-Álvarez, Complejo Asistencial Universitario de León, León (elviraleon009@hotmail.com)

Mercedes Freire, Complexo Hospitalario Universitario de A Coruña, La Coruña (mercedes.freire.gonzalez@sergas.es)

Marian Gantes, Hospital Universitario de Canarias, Tenerife

(gantesmar@hotmail.com)

Paloma García de la Peña, Hospital Madrid Norte Sanchinarro, Madrid (palomalefebvre@wanadoo.es)

Rosario García-Vicuña, Hospital Universitario de La Princesa, Madrid (vicuna111@gmail.com)

José Ángel Hernández-Beiraín, Hospital Insular de Gran Canaria, Las Palmas de Gran Canaria (hernandezberiain@yahoo.es) 
Loreto Horcada, Complejo Hospitalario de Navarra, Pamplona (mlhorcada@hotmail.com)

Jesús Ibañez-Ruán, Hospital Povisa, Vigo (jibanez@povisa.es) Mónica Ibañez, Hospital Son Llatzer, Palma de Mallorca (mibanez@hsll.es) Carlos Marras, Hospital Virgen de la Arrixaca, Murcia (cmarras2002@yahoo.es) José Luis Marenco, Hospital de Valme, Sevilla (jmarenco@gmail.com) Ivan Castellví, Hospital de Sant Pau, Barcelona (icastellvi@santpau.cat) Carlos Montilla-Morales, Hospital Clínico Universitario de Salamanca (montillamorales.carlos@gmail.com)

Mireia Moreno, Hospital Parc Taulí, Sabadell, Barcelona

(mmorenoma@cspt.es)

Ángela Pecondon-Español, Hospital Miguel Servet, Zaragoza

(apecondon@ono.com)

Esther Ruiz Lucea, Hospital de Basurto, Bilbao

(mariaesther.ruizlucea@osakidetza.net)

Ana Sánchez-Atrio, Hospital Universitario Príncipe de Asturias, Alcalá de Henares, Madrid (aisatrio@gmail.com)

Gregorio Santos-Soler, Hospital Marina Baixa, Villajoyosa, Alicante (santosgre@gmail.com)

Francisco Toyos, Hospital Universitario Virgen de la Macarena, Sevilla (toyos@arrakis.es)

Esther Uriarte Isacelaya, Hospital Universitario de Donosti, San Sebastián (esther.uriarteisacelaya@osakidetza.net)

Tomas Vazquez-Rodríguez, Hospital Universitario Lucus Augusti, Lugo (tomas.ramon.vazquez.rodriguez@sergas.es).

\section{Funding}

None. This study is not part of corporate sponsored research.

\section{Availability of data and materials}

The authors confirm that all data underlying the findings are fully available without restriction. All relevant data are within the article.

\section{Authors' contributions}

All of the authors collected and interpreted the data, were involved in drafting the manuscript or revising it critically for important intellectual content, have given final approval of the version to be published, and agreed to be accountable for all aspects of the work in ensuring that questions related to the accuracy or integrity of any part of the work are appropriately investigated and resolved.

\section{Ethics approval and consent to participate}

The study protocol was approved by the institutional ethics committee of the Hospital Universitario Doctor Negrín (Las Palmas de Gran Canaria) and subsequently by the local ethics committee of all participating centers. Informed consent was obtained from the patients, and their clinical records and information were anonymized prior to analysis. Confidential information of the patients was protected in accordance with national norms. This study was conducted in accordance with the principles of the Declaration of Helsinki and the International Conference for Harmonization.

\section{Consent for publication}

Informed consent was obtained from the patients, and their clinical records and information were anonymized prior to analysis. Confidential information of the patients was protected in accordance with national norms.

\section{Competing interests}

The authors declare that they have no competing interests.

\section{Publisher's Note}

Springer Nature remains neutral with regard to jurisdictional claims in published maps and institutional affiliations.

\section{Author details}

${ }^{1}$ Department of Rheumatology (Planta 10-2), Servicio de Reumatología, Hospital Universitario de Bellvitge, Feixa Llarga, s/n, Hospitalet de Llobregat, 08907 Barcelona, Spain. ${ }^{2}$ Unidad de Investigación, Sociedad Española de Reumatología, Madrid, Spain. ${ }^{3}$ Hospital Universitario Doctor Negrín, Las Palmas de, Gran Canaria, Spain. ${ }^{4}$ Hospital Universitario Gregorio Marañón, Madrid, Spain. ${ }^{5}$ Hospital Universitario 12 de Octubre, Madrid, Spain. ${ }^{6}$ Hospital Universitario Araba, Vitoria, Spain. ${ }^{7}$ Hospital Universitario de Málaga, Málaga,
Spain. ${ }^{8}$ Hospital Germans Trias i Pujol, Badalona, Barcelona, Spain. ${ }^{9}$ Hospital Universitario Puerta de Hierro, Madrid, Spain. ${ }^{10}$ Hospital Universitario Marqués de Valdecilla, Santander, Spain. ${ }^{11}$ Complexo Hospitalario Universitario de Vigo, Vigo, Spain.

\section{Received: 10 August 2018 Accepted: 25 November 2018 \\ Published online: 19 December 2018}

\section{References}

1. Torre $\mathrm{O}$, Harare S. Pleural and pulmonary involvement in systemic lupus erythematosus. Presse Med. 2011:40(1 Pt 2):e19-29.

2. Haye Salinas MJ, Caeiro F, Saurit V, Alvarellos A, Wojdyla D, Scherbarth HR, et al. Grupo Latino Americano De Estudio del Lupus (GLADEL). Pleuropulmonary involvement in patients with systemic lupus erythematosus from a Latin American inception cohort (GLADEL). Lupus. 2017;26:1368-77.

3. Cheema GS, Quismorio FP Jr. Interstitial lung disease in systemic lupus erythematosus. Curr Opin Pulm Med. 2000;6:424-9.

4. Keane MP, Lynch JP III. Pleuropulmonary manifestations of systemic lupus erythematosus. Thorax. 2000:55:159-66.

5. Haupt HM, Moore GW, Hutchins GM. The lung in systemic lupus erythematosus. Analysis of the pathologic changes in 120 patients. Am J Med. 1981;71:791-8.

6. Quadrelli SA, Alvarez C, Arce SC. Pulmonary involvement of systemic lupus erythematosus: analysis of 90 necropsies. Lupus. 2009;18:1053-60.

7. Carmier D, Marchand-Adam S, Diot P, Diot E. Respiratory involvement in systemic lupus erythematosus. Rev Mal Respir. 2010;27:e66-78.

8. Kamen DL, Strange C. Pulmonary manifestations of systemic lupus erythematosus. Clin Chest Med. 2010;31:479-88.

9. Zhao J, Bai W, Zhu P, Zhang X, Liu S, Wu L. Chinese SLE Treatment and Research group (CSTAR) registry VIl: prevalence and clinical significance of serositis in Chinese patients with systemic lupus erythematosus. Lupus. 2016;25:652-7.

10. Mitoo S, Fell CD. Pulmonary manifestations of systemic lupus erythematosus. Semin Respir Crit Care Med. 2014;35:249-54.

11. Pego-Reigosa JM, Medeiros DA, Isenberg DA. Respiratory manifestations of systemic lupus erythematosus: old and new concepts. Best Pract Res Clin Rheumatol. 2009;23:469-80.

12. Allen D, Fischer A, Bshouty Z, Robinson DB, Peschken CA, Hitchon C, ElGabalawy H, Meyers M, Mittoo S. Evaluating systemic lupus erythematosus patients for lung involvement. Lupus. 2012;21:1316-25.

13. Bertoli AM, Vila LM, Apte M, Fessler BJ, Bastian HM, Reveille JD, Alarcon GS, LUMINA Study Group. Systemic lupus erythematosus in a multiethnic US Cohort LUMINA XLVIII: factors predictive of pulmonary damage. Lupus. 2007;16:410-7.

14. Wan SA, Teh CL, Jobli AT. Lupus pneumonitis as the initial presentation of systemic lupus erythematosus: case series from a single institution. Lupus. 2016:25:1485-90.

15. Abud-Mendoza C, Diaz-Jouanen E, Alarcon-Segovia D. Fatal pulmonary hemorrhage in systemic lupus erythematosus. Occurrence without hemoptysis. J Rheumatol. 1985;12:558-61.

16. Borrell H, Narváez J, Alegre JJ, Castellví I, Mitjavila F, Aparicio M, et al. Shrinking lung syndrome in systemic lupus erythematosus: A case series and review of the literature. Medicine (Baltimore). 2016;95:e4626.

17. Hochberg M. Updating the American College of Rheumatology revised criteria for the classification of systemic lupus erythematosus. Arthritis Rheum. 1997:40:1725.

18. Rúa-Figueroa I, López-Longo FJ, Calvo-Alén J, Galindo-Izquierdo M, Loza E, García de Yebenes MJ, et al. Grupo de trabajo en Enfermedades Autoinmunes Sistémicas de la Sociedad Española de Reumatología (EASSER); Unidad de Investigación de la Sociedad Española de Reumatología (UI-SER). National registry of patients with systemic lupus erythematosus of the Spanish Society of Rheumatology: objectives and methodology. Reumatol Clin. 2014;10:17-24.

19. Petri M, Kim MY, Kalunian KC, Grossman J, Hahn BH, Sammaritano LR, et al. Combined oral contraceptives in women with systemic lupus erythematosus. N Engl J Med. 2005;353:2550-8.

20. Gladman D, Ginzler E, Goldsmith C, Fortin P, Liang M, Urowitz M, et al. The development and initial validation of the Systemic Lupus International Collaborating Clinics/American College of Rheumatology Damage Index for systemic lupus erythematosus. Arthritis Rheum. 1996;39:363-9. 
21. Isenberg DA, Rahman A, Allen E, Farewell V, Akil M, Bruce IN, D'Cruz D, et al. BILAG 2004. Development and initial validation of an updated version of the British Isles Lupus Assessment Group's disease activity index for patients with systemic lupus erythematosus. Rheumatology (Oxford). 2005:44:902-6.

22. Yee CS, Farewell V, Isenberg DA, Prabu A, Sokoll $K$, Teh LS, et al. Revised British Isles Lupus Assessment Group 2004 index: a reliable tool for assessment of systemic lupus erythematosus activity. Arthritis Rheum. 2006; 54:3300-5.

23. Cervera R, Abarca-Costalago M, Abramovicz D, Allegri F, Annunziata P, Aydintug AO, et al. Systemic lupus erythematosus in Europe at the change of the millennium: lessons from the "Euro-Lupus Project". European Working Party on Systemic Lupus Erythematosus. Autoimmun Rev. 2006;5:180-6.

24. Zamora MR, Warner ML, Tuder R, Schwarz MI. Diffuse alveolar hemorrhage and systemic lupus erythematosus. Clinical presentation, histology, survival, and outcome. Medicine (Baltimore). 1997:76:192-202.

25. Dell'Era L, Corona F, Defilippi AC, Esposito A, Principi N, Esposito S. Systemic lupus erythematosus presenting with pulmonary thromboembolism in a 15year-old girl. Rheumatol Int. 2012;32:2925-8.

26. Somers E, Magder LS, Petri M. Antiphospholipid antibodies and incidence of venous thrombosis in a cohort of patients with systemic lupus erythematosus. J Rheumatol. 2002;29:2531-6.

27. Zuily S, Wahl D. Pulmonary hypertension in antiphospholipid syndrome. Curr Rheumatol Rep. 2015;17:478.

28. Gertner E. Diffuse alveolar hemorrhage in the antiphospholipid syndrome: spectrum of the disease and treatment. J Rheumatol. 1999;26:805-7.

29. Hughson MD, He Z, Henegar J, McMurray R. Alveolar hemorrhage and renal microangiopathy in systemic lupus erythematosus. Arch Path Lab Med. 2001;125:475-83.

30. Asherson RA, Greenblat MA. Recurrent alveolar hemorrhage and pulmonary capillaritis in the primary antiphospholipid syndrome. J Clin Rheumatol. 2001;7:30-3.

31. Paran D, Fireman E, Elkayam O. Pulmonary disease in systemic lupus erythematosus and the antiphospholpid syndrome. Autoimmun Rev. 2004; $3: 70-5$

32. Li EK, Tam LS. Pulmonary hypertension in systemic lupus erythematosus: clinical association and survival in 18 patients. J Rheumatol. 1999;26:1923-9.

33. Shen JY, Chen SL, Wu YX, Tao RQ, Gu YY, Bao CD, et al. Pulmonary hypertension in systemic lupus erythematosus. Rheumatol Int. 1999;18:147-51.

34. Wang J, Qian J, Wang Y, Zhao J, Wang Q, Tian Z, et al. Serological biomarkers as risk factors of SLE-associated pulmonary arterialhypertension: a systematic review and meta-analysis. Lupus. 2017;26:1390-400.

35. Deeb M, Tselios K, Gladman DD, Su J, Urowitz M. Shrinking lung syndrome in systemic lupus erythematosus: a single-centre experience. Lupus. 2018;27: 365-71.

36. Duron L, Cohen-Aubart F, Diot E, Borie R, Abad S, Richez C, et al. Shrinking lung syndrome associated with systemic lupus erythematosus: A multicenter collaborative study of 15 new cases and a review of the 155 cases in the literature focusing on treatment response and long-term outcomes. Autoimmun Rev. 2016;15:994-1000.

37. Pan TL, Thumboo J, Boey ML. Primary and secondary pulmonary hypertension in systemic lupus erythematosus. Lupus. 2000;9:338-42.

38. Mochizuki T, Aotsuka S, Satoh T. Clinical and laboratory features of lupus patients with complicating pulmonary disease. Respir Med. 1999;93:95-101.

39. Boulware DW, Hedgpeth MT. Lupus pneumonitis and anti-SSA (Ro) antibodies. J Rheumatol. 1989;16:479-81.

40. Pego-Reigosa JM, Lois-Iglesias A, Rúa-Figueroa I, Galindo M, Calvo-Alén J, de Uña AJ, et al. Relationship between damage clustering and mortality in systemic lupus erythematosus in early and late stages of the disease: cluster analysis in a large cohort from the Spanish Society of Rheumatology Lupus Registry. Rheumatology (Oxford). 2016;55:1243-50.

41. Abu-Shakra M, Urowitz MB, Gladman DD, Gough J. Mortality studies in systemic lupus erythematosus. Results from a single center. I Causes of death. J Rheumatol. 1995;22:1259-64.

42. Abu-Shakra M, Urowitz MB, Gladman DD, Gough J. Mortality studies in systemic lupus erythematosus. Results from a single center. II Predictor variables for mortality. J Rheumatol. 1995;22:1265-70.

\section{Ready to submit your research? Choose BMC and benefit from:}

- fast, convenient online submission

- thorough peer review by experienced researchers in your field

- rapid publication on acceptance

- support for research data, including large and complex data types

- gold Open Access which fosters wider collaboration and increased citations

- maximum visibility for your research: over $100 \mathrm{M}$ website views per year

At BMC, research is always in progress.

Learn more biomedcentral.com/submissions 